\title{
ANALISIS AUDIT SISTEM INFORMASI BERBASIS COBIT 5 PADA SUBDOMAIN APO11 MANAGE QUALITY
}

\author{
Christopher Hansel Kuntadihardja ${ }^{1}$, Andeka Rocky Tanaamah ${ }^{2}$ \\ ${ }^{1,2}$ Fakultas Teknologi Informasi, Universitas Kristen Satya Wacana
}

\section{Article Info:}

Dikirim: 27 Mei 2019

Direvisi: 10 Juni 2019

Diterima: 20 Juni 2019

Tersedia Online: 29 Juni 2019

Penulis Korespondensi:

Christopher Hansel Kuntadihardja Program Studi Sistem Informasi,

Fakultas Teknologi Informasi,

Universitas Kristen Satya Wacana,

Salatiga, Indonesia

Email:

682015003@student.uksw.edu
Abstrak: Pengelolaan Teknologi Informasi (TI) dapat digunakan untuk menjamin efisiensi dan penerapan manajemen kualitas, sehingga proses bisnis setiap perusahaan atau organisasi dapat berjalan dengan baik, dan juga sesuai dengan tujuan utama perusahaan. Maka dari itu dibutuhkan pengelolaan dan peniliaian terhadap manajemen kualitas yang diterapkan di suatu perusahaan. Analisis audit sistem informasi pada penelitian ini menggunakan framework COBIT 5 yang berfokus pada domain Align, Plan, and Organise (APO) yaitu APO11 Manage Quality. Penilaian level kapabilitas akan dilakukan terhadap APO11 Manage Quality pada divisi di sebuah perusahaan ritel yang sudah menggunakan teknologi informasi dalam setiap proses bisnisnya. Peniliaian level kapabilitas APO11 dilakukan untuk evaluasi terhadap penerapan manajemen kualitas yang ada di divisi. Hasil keseluruhan pengukuran manajemen kualitas di divisi ini mencapai level 2 (Manage process). Dari hasil level yang diperoleh, disusun rekomendasi yang dapat diterapkan oleh divisi ini agar level kapabilitas APO11 mencapai level yang diinginkan yaitu level 3 (Established processs) sehingga dapat mendukung proses bisnis perusahaan dari sisi teknologi informasi.

Kata kunci: framework cobit 5; manajemen kualitas; level kapabilitas.

\begin{abstract}
Information Technology Management (IT) can be used to ensure efficiency and implementation of quality management, so that the business processes of each company or organization can run well, and also in accordance with the company's main objectives. Therefore, management and assessment of the quality management applied in a company is needed. Analysis of the information system audit in this study uses the COBIT 5 framework that focuses on the domain Align, Plan, and Organize (APO), namely the APO11 Manage Quality. Assessment of capability level will be carried out on APO11 Manage Quality in a division in a retail company that has used information technology in every business process. Assessment of APO11 capability level was conducted to evaluate the implementation of quality management in the division. The overall results of measuring quality management in this division reach level 2 (Manage process). From the results of the levels obtained, recommendations are made that can be applied by this division so that the level of capability of APO11 reaches the desired level, namely level 3 (Established processes) so that it can support the company's business processes from the information technology side.
\end{abstract}

Keywords: cobit 5 framework; manage quality; capability level. 


\section{PENDAHULUAN}

Perkembangan teknologi informasi yang ada sekarang merupakan investasi organisasi/perusahaan untuk menuju visi dan misinya, dan menjadikan teknologi informasi sebagai penunjang dari setiap proses bisnis organisasi/perusahaan. Pengunaan teknologi informasi tidak hanya dimanfaatkan oleh organisasi/perusahaan yang bertujuan keunutngan namun dimanfaatkan juga oleh organisasi/perusahaan yang tidak bertujuan tidak meraih keuntungan. Selain itu diinginkan kesamaan antara proses bisnis dan proses pada teknologi informasi sehingga dapat saling mendukung dalam mencapai tujuan utama organisasi/perusahaan. Saat ini semua perusahaan sudah melakukan investasi TI baik untuk skala yang kecil maupun yang besar karena mereka sadar bahwa TI memiliki peranan pentig untuk memciptakan proses bisnis yang efektif dan efisien sehingga menambahkan nilai lebih untuk perusahaan mereka. [1] TI menjadi bagian yang sangat penting baik untuk pertumbuhan dan perkembangan perusahaan dan melihat persaingan pasar. Oleh karena itu, sangat diperlukan adanya penerapan TI yang benar dalam sistem yang mendukung proses bisnis perusahaan. Pada suatu perusahaan, tata kelola dilakukan dengan melaksanakan audit. Audit teknologi informasi atau Audit sistem informasi adalah suatu cara pengawasan dan pengendalian untuk infrastruktur IT/IS secara keseluruhan. [2] Pentingnya dilakukannya audit sitem informasi didukung dengan empat tujuan utama yaitu; mengontrol asset, memelihara integritas data, melindungi efektivitas sistem, dan mencapai efisiensi. [3]

Yogya Group merupakan perusahaan ritel dengan bentuk pasar swalayan, toserba, dan pusat jajanan atau makanan yang menjadi satu kesatuan toko.Yogya memiliki misi yaitu setia memenuhi kebutuhan masyarakat. Kantor pusat YOGYA Group berada di Jalan Terusan Buah Batu No. 12 Bandung, Jawa Barat. Awalnya Yogya adalah sebuah toko yang menjual batik dengan nama pertama Djokdja di Bandung yang dimiliki oleh Bapak Boedi pada tahun 1948. Seiring berjalannya waktu, pada tahun 1972 toko Djokja tidak hanya menjual produk batik, tetapi juga menjual barang-barang pokok sehari-hari. Dan pada tanggal 28 Oktober 1982, toko Djokja berubah nama menjadi toserba Yogya sekaligusmembuka toko cabang pertama di Jalan Sunda No. 60 Bandung, Jawa Barat. Tahun demi tahun toserba Yogya terus bertumbuh dan berkembang dengan cepat. Sekarang toserba Yogya telah menaungi beberapa satuan bisnis, diantaranya toserba Griya, Yogya Xpress, dan Yomart minimarket.

Yogya Group memiliki berbagai departemen untuk mendukung berjalannya proses bisnis perusahaan, salah satunya yaitu departemen TI yang berperan sebagai perencangan sistem untuk menunjang kegiatan bisnis, yang terdiri dari: IT Operation \& infrastructure, IT Software Development dan IT Product \& Information Solution. Terutama di divisi IT Product \& Information yang memiliki sub divisi IT Product Solution (ITPS), dimana sub divisi ini memiliki peranan penting yang menampung segala permintaan solusi TI dari departemen lain yang kaitannya untuk meningkatkan kinerja dan kuliatas layanan, sehinga proses bisnis terus bisa berjalan tidak ada yang terhambat. Divisi ITPS memiliki bagian yaitu ; Project Coordinator, Bussines Analyst, dan Software Architect, mereka semua bekerja sama untuk merancang sistem yang bisa menjadi solusi TI yang berguna bagi departemen lain yang membutuhkan.

Dalam penelitian ini, peneliti menggunakan standar kontrol umum terhadap teknologi informasi yaitu Control Objectives for Information and related Technology 5 (COBIT 5) merupakan produk dari Information System Audit and Control Association (ISACA) merupakan framework IT yang dipakai pada kerangka kerja untuk melaksanakan audit karena COBIT 5 adalah kerangka kerja yang memiliki standar internasional yang menyediakan kerangka kerja IT Govenance dan Control Objectives dengan panduan umum tindakan, indikator, proses dan praktik terbaik untuk membantu divisi ITPS dalam mendukung proses bisnis utama PT. Akur Pratama (Yogya Group) dari sisi TI.

Penulis memilih sub domain Align, Plan, Organise 011 (APO11) tentang Manage Quality dari domain APO. Saat ini belum ada ukuran keseluruhan yang jelas untuk kualitas dari proses bisnis yang menghasilkan solusi IT oleh divisi ITPS, sebagai dasar mengetahui dan meningkatkan manajemen kualitas. Dengan keadaan yang ada saat ini, diperlukan proses penghitungan tingkat kematangan untuk mengetahui dan meningkatkan manajemen kualitas di divisi ITPS. Oleh karena itu dibutuhkan audit terhadap manajemen kualitas di divisi ITPS agar solusi TI yang dihasilkan berguna bagi departemen lain dan mendukung kegiatan bisnis PT. Akur Pratama (Yogya Group). Sehingga dari permasalahan yang timbul membuat penulis ingin mengetahui dan melakukan evaluasi terhadap manajemen kualitas di divisi ITPS PT. Akur Pratama (Yogya Group), sehingga mampu memberikan rekomendasi terhadap pelaksananmanajemen kualitas pada project yang akan menghasilkan solusi TI agar strategi bisnis berjalan dengan baik dan memberikan pelayanan terbaik kepada departemen lainnya.

Beberapa referensi yang dijadikan sebagai tinjauan pustaka dalam penelitian ini yang dilakukan oleh Cantika Pragita. Bertujuan untuk meningkatkan manajemen kualitas di sebuah organisasi, hasil yang didapat untuk domain APO11 mencapai level kapabilitas 3, artinya sedang menuju level kapabilitas 4, dan target level lapabilitas sama dengan level kapabilitas yang ditujunya yaitu level 4. [4]

Berikutnya, penelitian yang dilakukan oleh Aris Irwanto, Dkk, dalam penelitiannya membahas audit sistem informasi pada audit laporan keuangan di instansi. Hasil yang didapat diantaranya proses APO7 dengan level kapabilitas rata-rata 4,5, APO13 berada pada level kapabilitas rata-rata 4,42, DSS02 berada pada level kapabilitas rata-rata 4,28, APO03 berada pada level kapabilitas rata-rata 4,25, DSS05 berada pada level kapabilitas rata-rata 4,2, DSS03 MEA02 berada pada level kapabilitas rata-rata 4,22, dan MEA03 berada pada 
level kapabilitas rata-rata 4,22. 8 proses COBIT 5 yang terpilih dapat dijadikan acuan untuk melakukan audit sistem informasi keuangan pada audit laporan keuangan di sebuah instansi. [5]

Kemudian penelitian yang dilakukan M. Ilham Nur Faizin berbeda, penelitian ini bertujuan untuk menciptakan alat dalam bentuk checklist yang dapat mempermudah mengetahui tercapainya tujuan dan level kapabilitas proses tata kelola TI pada buku Panduan Umum Tata Kelola Teknologi Informasi dan Komunikasi Nasional (PTK) dimana dalam PTK tersebut tidak semua proses pada domain APO dalam COBIT 5 tercantum dalam PTK. Kesimpulan yang di dapat dari penelitian tersebut adalah penambahan ukuran penggunaan mekanisme shared-service dalam pencapaian tujuan proses APO03, dan penambahan batasan frekuensi pengukuran pada kriteria level kapabilitas, dan pembuatan alat pengukuran level kapabilitas dilakukan untuk auditor dan auditee. Sehingga diketahui bahwa alat yang dibuat memiliki fitur yang mudah dipahami, navigasi yang mudah dipahami, dan juga memiliki pengelolaan yang baik dan akurat. [6]

Perbedaan dengan penelitian yang lainnya adalah pada penelitian ini akan lebih fokus pada audit sistem informasi untuk mengetahui dan mengukur tingkat manajemen kualitas di divisi IT Product Solution secara menyeluruh mulai dari prosedur, sistem, dan pembagian kerja menggunakan framework COBIT 5 spesifiknya pada sub domain APO yaitu APO11 tentang Manage quality, karena selama ini belum ada pengukuran kualitas di divisi ITPS dalam proses pengerjaan setiap project yang menghasilkan sebuah sistem/aplikasi dimana dijadikan solusi TI dan sangat mempengaruhi kegiatan bisnis tiap departemen dan menunjang bisnis utama PT. Akur Pratama Yogya Group. Berbeda dengan penelitian yang lainnya, dimana penelitian terdahulu berfokus untuk meningkatkan kualitas serta memperbaiki dan menambahkan tools untuk penerapan Domain APO dalam COBIT 5 tercakup dalam buku PTK, dan yang berbeda dari penelitian sebelumnya adalah penulis ingin mengetahui, melakukan evaluasi tentang manajemen kualitas berdasarkan sub domain APO11 serta memberikan rekomendasi. Semua informasi yang di dapat didukung dengan melakukan observasi yang mendalam selama 3 bulan dan ikut serta menjadi bagian di divisi ITPS mengerjakan proyek dan menghasilkan solusi TI.

\section{METODOLOGI PENELITIAN}

Metodologi penelitian berbeda dengan metode penelitian, istilah keduanya sering sekali dipakai dipakai bergantian karena mempunya arti yang hampir mirip. Metodologi penelitian memiliki arti prinsip dasar tentang prosedir yang dilakukan dalam tahap penelitian. [7] Penelitian ini menggunakan penelitian deskriptif kualitatif, yaitu hasil pengumpulan data berdasarkan fenomena-fenomena yang ada atau berdasarkan fakta dan mengarah terhadap karakteristik, kualitas, impliaksi antar kegiatan. [8] Beberapa fase - fase audit yang terdiri dari identifikasi masalah, pengumpulan data, analisa data, dan rekomendasi.

\subsection{Identifikasi Masalah}

Identifikasi masalah merupakan tahap awal melakukan penelitian untuk mencari, menemukan, mengumpulkan, dan mencatat data dan informasi mengenai permasalahan yang muncul pada objek penelitian. Tahap awal yang dilakukan adalah mengetahui dan memahami proses bisnis dan penerapan TI perusahaan yang akan di audit. Pemahaman didapat dengan cara mengamati langsung setiap proses bisnis yang berjalan dan melakukan pembelajaran pada setiap dokumen yang menjadi pedoman pelaksanaan proses bisnis perusahaan. Bentuk dokumennya adalah struktur organisasi perusahaan, standard operating proscedure, portfolio, infrastruktur TI, dan manajemen proyek yang dimiliki.

\subsection{Pengumpulan Data}

Penelitian ini menerapkan proses pengumpulan data dengan cara observasi dan wawancara di divisi $I T$ Product Solution (ITPS) PT. Akur Pratama (Yogya Group) Kota Bandung, anara lain:

a. Observasi

Observasi adalah pengamatan langsung dengan tujuan mengetahui dan memahami pengetahuan dari suatu objek yang diteliti, sehingga memperoleh data dalam bentuk informasi-informasi yang dibutuhkan untuk penelitian.

b. Wawancara

Wawancara adalah cara mendapatkan data dan informasi dengan menanyakan secara langsung kepada narasumber. Membahas mengenai tata kelolaTI, dan kondisi manajemen kualitas yang ada di divisi ITPS PT. Akur Pratama (Yogya Group) Kota Bandung.

\subsection{Analisa Data}

Terdapat dua tahapan melakukan analisis data dalam audit, diantaranya:

a. Analisis Level Kapabilitas (CapabilityLevel)

Kapabilitas level yang diberikan oleh COBIT 5 terdiri dari 6 yaitu level 0 - level 5, diantaranya level 0 yaitu Incomplete Process, level 1 yaitu Performed Process, level 2 yaitu Managed Process, level 3 yaitu 
Established Process, level 4 yaitu Predictable Process, level 5 yaitu Optimizing Process. Semua proses yang dinilai akan menciptakan 4 level diantaranya; Not achieved $(\mathrm{N})$, dengan hasil penilaian antara $0 \%$ $15 \%$, Partially achieved (P), dengan hasil penilaian $>15 \%-50 \%$, Largely achieved (L), dengan hasil penilaian $>50 \%-85 \%$, Fully achieved (F), dengan hasil penilaian $>85 \%-100 \%$. [9]

b. Analisis Kesenjangan (Gap)

Tujuan dilakukannya analisis kesenjangan adalah untuk mengetahui selisih dari level kapabilitas yang didapat dibandingkan dengan level target yang diinginkan. Penentuan level target, ditentukan dengan level yang sedang dituju dari level rata - rata yang didapat.

\subsection{Rekomendasi}

Rekomendasi adalah bentuk saran dari auditor yang sifatnya menganjurkan untuk membantu menyelesaikan masalah yang ada. Rekomendasi didapat dari hasil kapabilitas level proses TI saat ini dan kapabilitas yang diinginkan. Rekomendasi yang diberikan diharapkan mampu membantu memberikan solusi yang tepat terhadap manajemen kualitas yang dimiliki perusahaan. Rekomendasi akan disusun berdasarkan kondisi sesungguhnya yang terjadi di perusahaan.

\section{HASIL DAN PEMBAHASAN}

\subsection{Hasil Observasi dan Wawancara}

Observasi secara langsung dilakukan untuk mencari dan mendukung informasi yang diperlukan untuk subdomain Align, Plan, Organise (APO11) untuk mengevaluasi manajemen kualitas. Hasil Observasi menunjukkan bahwa pada divisi IT Product Solution (ITPS) PT. Akur Pratama (Yogya Group) Kota Bandung sudah melaksanakan manajemen kualitas yang dibuktikan dengan adanya penerapan beberapa dokumen.

Kemudian wawancara dilakukan dengan menggunakan checklist pertannyaan sesuai standart Control Objectives for Information and Related Technology 5 (COBIT 5) kepada beberapa narasumber. Narasumber wawancara terdiri dari staff di divisi ITPS, Chief ITPS, staff dari divisi lain dalam lingkup departemen TI, dan juga staff dari department lain sebagai user dari beberapa proyek. Hasil wawancara didapatkan beberapa informasi yang dapat dijadikan sebagai hasil temuan dan dijadikan sebagai ukuran untuk menentukan level kapabilitas dari proses TI dan manajemen kualitas di divisi ITPS.

\subsection{Penerapan COBIT 5}

\subsubsection{Raci Chart}

Diagram RACI merupakan komponen dari Rensponsibility Assignment Matrix (RAM) yang memiliki arti pemetaan antara sumber daya dengan aktivitas dalam setiap metode. pengerttian RACI adalah; Responsible (R) adalah orang yang memiliki tanggungjawab melakukan dan menyelesaikan kegiatan, Accountable (A) merupakan orang yang memberi arahan terhadap jalannya suatu kegiatan, Consulted (C) adalah orang yang akan menjadi wadah untuk konsultasi dan memberikan nasihat dalam kegiatan, Informed (I) adalah orang yang diberitahu informasi tentang jalannya suatu kegiatan. [10] Penelitian ini menggunakan Raci Chart yang dikhususkan untuk penilaian proses di domain APO11 COBIT 5, seperti yang tertera pada gambar di bawah. [11]

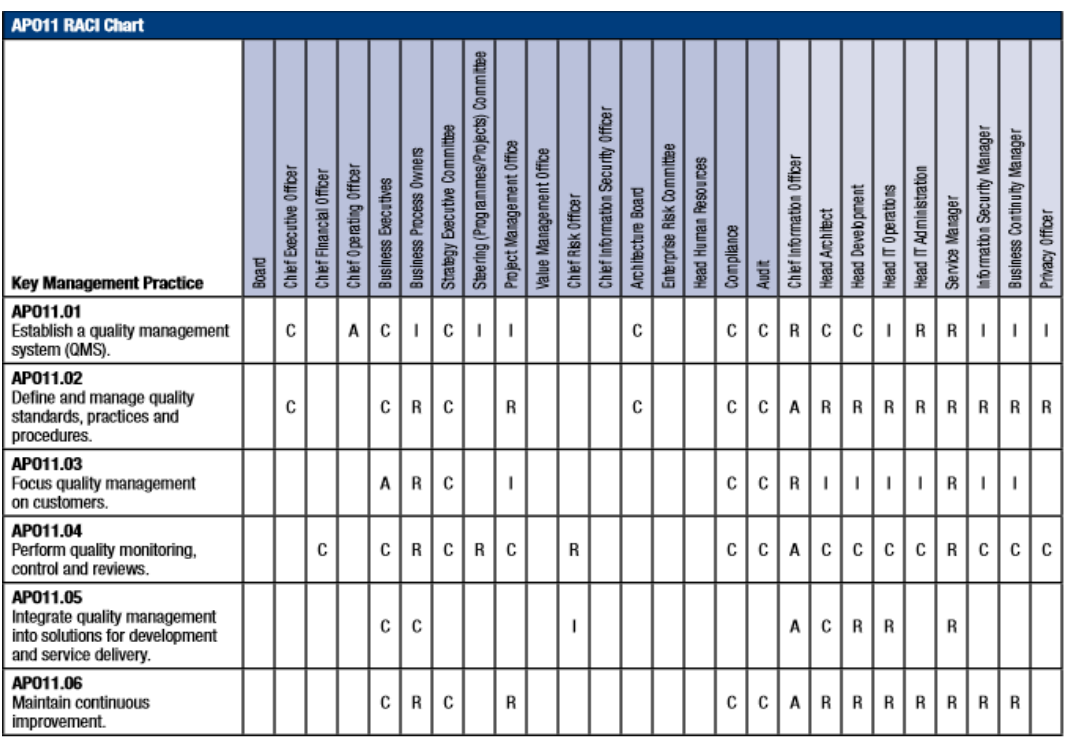

Gambar 1. Diagram RACI Chart APO11 [9] 


\subsubsection{Pemetaan Enterprise Goal}

Pemetaan Enterprise Goals untuk menyelaraskan tujuan strategis divisi ITPS dengan Enterprise Goals (EG) dalam COBIT 5. Untuk proses analisisnya akan dilihat keterkaitan antara tujuan strategis Divisi IT Product Solution dengan Enterprise Goals COBIT 5. Berikut adalah proses analisis keterkaitan tujuan strategis Divisi ITPS terhadap Enterprise Goals COBIT 5:

Tabel 1. Pemetaan tujuan bisnis divisi IT product solution ke dalam enterprise goals

\begin{tabular}{|c|c|c|c|}
\hline No & $\begin{array}{c}\text { Kode Enterprise } \\
\text { Goals COBIT } 5\end{array}$ & Deskripsi & $\begin{array}{c}\text { Keterkaitan dengan } \\
\text { Enterprise Goals Divisi }\end{array}$ \\
\hline 1 & EG1 & $\begin{array}{l}\text { Stakeholder value of business } \\
\text { Investment }\end{array}$ & Ada keterkaitan \\
\hline 2 & EG2 & $\begin{array}{l}\text { Portofolio of competitive } \\
\text { products and services }\end{array}$ & Ada keterkaitan \\
\hline 3 & EG3 & $\begin{array}{l}\text { Managed business } \\
\text { risks(Safeguarding assets) }\end{array}$ & Ada keterkaitan \\
\hline 4 & EG5 & Financial Transparency & Ada keterkaitan \\
\hline 5 & EG6 & $\begin{array}{l}\text { Customer oriented service } \\
\text { Culture }\end{array}$ & Ada keterkaitan \\
\hline 6 & EG7 & $\begin{array}{l}\text { Business service continuity and } \\
\text { Availability }\end{array}$ & Ada keterkaitan \\
\hline 7 & EG8 & $\begin{array}{l}\text { Agile responses to a changing } \\
\text { business environment }\end{array}$ & Ada keterkaitan \\
\hline 8 & EG9 & $\begin{array}{l}\text { Information based strategic decision } \\
\text { making }\end{array}$ & Ada keterkaitan \\
\hline 9 & EG10 & Optimisation of service delivery costs & Ada keterkaitan \\
\hline 10 & EG11 & $\begin{array}{l}\text { Optimisation of business process } \\
\text { functionality }\end{array}$ & Ada keterkaitan \\
\hline 11 & EG12 & Optimisation of business process costs & Ada keterkaitan \\
\hline 12 & EG14 & $\begin{array}{l}\text { Operational and staff } \\
\text { Productivity }\end{array}$ & Ada keterkaitan \\
\hline 13 & EG15 & $\begin{array}{l}\text { Compliance with internal } \\
\text { Policies }\end{array}$ & Ada keterkaitan \\
\hline 14 & EG16 & Skilled and motivated people & Ada keterkaitan \\
\hline 15 & EG17 & $\begin{array}{l}\text { Product and business innovation } \\
\text { Culture }\end{array}$ & Ada keterkaitan \\
\hline
\end{tabular}

Pada tabel 1 dijelaskan hasil pemetaan Enterprise Goal dengan tujuan strategis divisi ITPS, dimana Enterprise Goal yang terpilih diantaranya; EG01 - EG03, EG05 - EG12, dan EG14 - EG17. Selanjutnya akan dilanjutkan ke tahap pemetaan IT- Related Goal.

\subsubsection{Pemetaan IT-Related Goal}

Proses selanjutnya adalah pemetaan IT-Related Goals dari COBIT 5 terhadap Enterprise Goals (EG). Sama seperti pemetaan yang sebelumnya. Kemudian Enterprise Goals yang sudah terpilih dipetakan ke dalam ITRelated Goals dapat dilihat pada tabel 2 terlihat implikasi yang kuat secara objek antara Enterprise Goals COBIT 5 yang terpilih dengan IT-realted Goals yang ditunjukkan dengan simbol P (primary key) yang memiliki keterkiatan sehingga terpilih, dan simbol S (secondary key) yang terkait namun tidak dominan yang membuat tidak terpilih. 


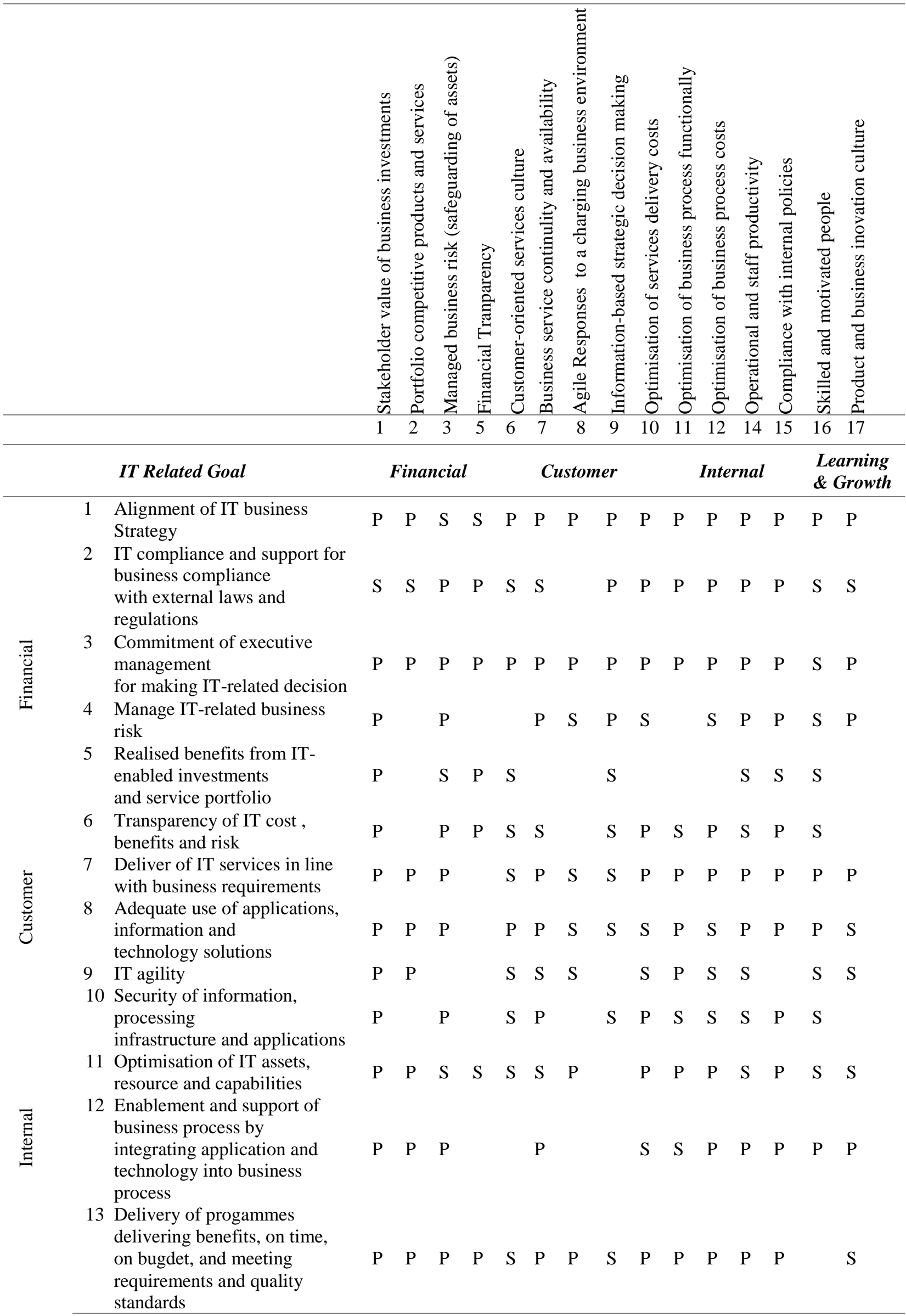




\section{Enterprise Goal}

14 Availability of realiable and useful information for decision $\mathrm{P}$ making

15 IT compliance with internal policies

$$
\begin{array}{lllllllllllllllll}
\mathrm{P} & & \mathrm{S} & \mathrm{P} & \mathrm{P} & \mathrm{S} & \mathrm{S} & \mathrm{P} & \mathrm{P} & \mathrm{S} & \mathrm{S} & \mathrm{S} & \mathrm{S} & \mathrm{S} & \\
& & & & & & & & & & & & & \\
\mathrm{P} & \mathrm{P} & & \mathrm{S} & \mathrm{S} & \mathrm{S} & & & \mathrm{S} & \mathrm{S} & \mathrm{P} & \mathrm{S} & \mathrm{P} & \mathrm{S} \\
& & & & & & & & & & & & & & & & \\
\mathrm{P} & & & \mathrm{S} & \mathrm{S} & \mathrm{P} & \mathrm{S} & \mathrm{S} & \mathrm{S} & \mathrm{S} & \mathrm{P} & \mathrm{S} & \mathrm{S} & \mathrm{P}
\end{array}
$$

16 Competent and motivated business and IT personnel

17 Knowledge, expertise and intiatives for business innovation

Hasil dari pemetaan IT-Related goals pada Tabel 2 di atas adalah terpilihnya semua IT Related goals, Keterangan dari pemetaan tabel diatas apabila pada suatu IT-Related Goals tidak terdapat nilai "P" yang berarti primary, maka IT-Related Goals tersebut tereliminasi. Kemudian IT-Related Goals yang terpilih dipetakan ke dalam proses pada Subdomain APO11 COBIT 5.

\subsubsection{Pemetaan Proses Control Subdomain APO11}

Pemetaan memiliki tujuan untuk menetapkan antara IT-Related Goals dengan Proses TI yang harus di jalankan. Sama seperti pemetaan sebelumnya antara Enterprise Goals terhadap IT-Related Goals, proses APO11 juga menggunakan primary key (P) sebagai acuan. Dalam penelitian ini berfokus pada mendefinisikan dan mengkomunikasikan persyaratan kualitas, pemantauan, dan pelaksannan proses TI yang sesuai standar yang ada, untuk tujuan keinginan melakukan perbaikan terus-menerus dan efisiensi. Dapat dilihat pada tabel dibawah ini:

Tabel 3. Pemetaan IT-related goals terhadap subdomain APO11

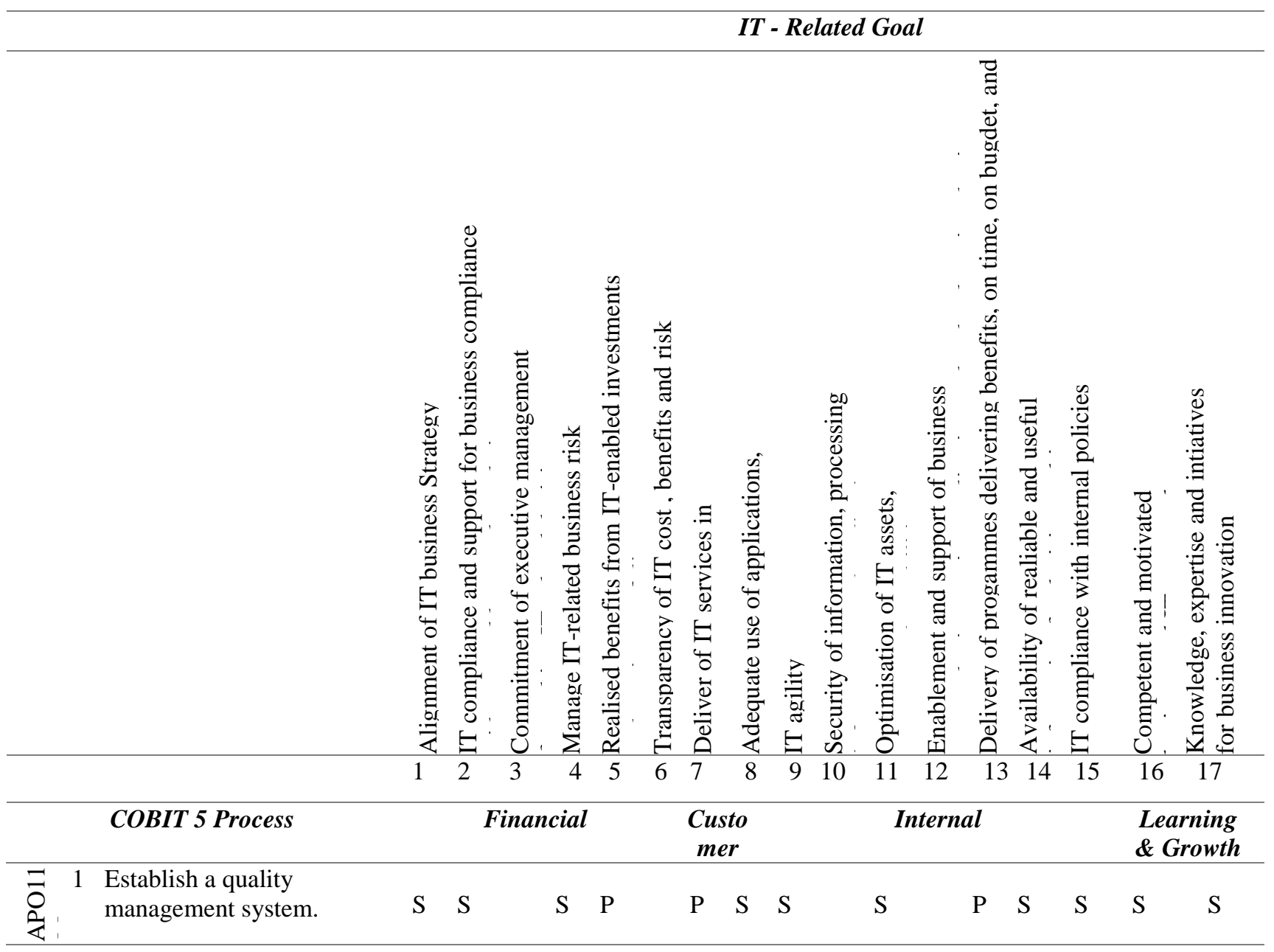




\section{IT - Related Goal}

2 Define and manage quality standarts, practices and procedures.

3 Focus quality management on customers.

4 Perfom quality monitoring, control and review.

S S

S S

$S \quad S$

$\begin{array}{lll}S & P & P\end{array}$

S S

S P

S S

6 Maintain continuous improvement.

management into solutions

for

development and service

delivery.

Pada tabel 3 domain yang di pakai adalah domain Align, Plan, Organise (APO) sub domain APO11 Manage Quality. Penjelasan dari APO11 adalah mengartikan dan mengkomunikasikan syarat - syarat kualitas pada seluruh prosedur, proses, dan hasil termasuk pemantauan, juga pelaksanaan praktek dan standar dalam upaya perbaikan secara terus-menerus dan efisiensi. Tujuan dari APO11 adalah untuk mengetahui dan meyakinkan pencapaian solusi dan layanan diberikan secara konsisten guna terpenuhinya syarat - syarat kualitas pada perusahaan dan memenuhi kebutuhan stakeholder.

\subsubsection{Hasil Temuan APO11 (Manage Quality)}

Hasil wawancara yang di dapat adalah berupa temuan mengenai sejauh mana setiap proses bisnis di divisi ITPS menerapkan manajemen kualitas, dan melakukan pemantauan agar setiap solusi dan layanan yang diberikan konsisten dan mampu bergerak ke arah yang lebih baik lagi. Lalu hasil temuan yang ada dapat digunakan untuk menghitung capability level pada tiap proses TI. Berikut adalah temuan pada tiap sub proses pada APO11 Manage Quality:

a. APO11.01 Establish a quality management system.

Berdasarkan audit yang dilakukan pada cakupan sub domain APO11, proses ini dilakukan untuk menilai sejauh man pencapaian aktivitas yang dilakukan oleh divisi kaitannya dalam membangun sistem manajemen kualitas. Hasil temuan dan bukti yang di dapat sesuai dengan kondisi di divisi ITPS, divisi ini sudah memiliki Standard Operating Procedure (SOP) dalam mengerjakan proyek yang menjadi acuan untuk setiap aktivitas - aktivitas kerja yang dilakukan dalam proyek. Selain itu juga struktur organisasi dan tata kerja sudah jelas sehingga hak dan kewajiban setiap posisi berjalan dengan baik. Divisi ITPS juga memiliki balance scorecard berisi sasaran kerja yang jelas dan didukung dengan adanya dokumen evaluasi untuk setiap proyek.

b. APO11.02 Define and manage quality standarts, practices and procedures.

Berdasarkan audit yang dilakukan pada cakupan sub domain APO11, Proses ini ada untuk mengukur sejauh mana pencapaian aktivitas yang dilakukan oleh divisi untuk menentukan dan mengelola, dan mengatur standar kualitas pelaksanaan dan prosedur. Hasil dan bukti yang di dapat sesuai dengan kesesuaiaan kondisi di divisi IT Product Solution, dimana adanya penerapan program onboarding dan offboarding dan juga adanya dokumen Employee Handbook untuk pegawai baru agar mereka mengenal budaya, sistem kerja, dan adanya Key Result Areas (KPA) dan Key Performance Indicators (KPI) untuk setiap bagian pekerjaan. [12] Divisi ini juga memiliki standar manajemen kualitas yang ada di dokumen sasaran mutu. Dalam menjalankan layanan divisi ITPS memiliki beberapa modul untuk setiap proses bisnis, dan dalam setiap modul berisi SOP, Work Intruction (WI), dan Form. Selain itu divisi ITPS memiliki enterprise architecture yang dikelola oleh pegawai yang ada, tetapi masih bergantung Chief IT Product Solution, dan memiliki dokumen resource allocation untuk setiap bagian pekerjaan untuk menjaga kualitas proyek dan mencegah penundaan pengerjaan proyek. Namun pengerjaan proyek terkadang terlambat karena Person in charge (PIC) dari proyek mengerjakan dua proyek secara bersamaan, dan adanya rangkap jabatan yang seringkali berpengaruh pada pengerjaan proyek.

c. APO11.03 Focus quality managemen on customers.

Berdasarkan audit yang dilakukan pada cakupan sub domain APO11, Proses ini ada untuk mengukur sejauh mana pencapaian aktivitas yang ada di divisi dalam menerapkan manajemen kualitas fokus pada pelanggan (customer). Hasil dan bukti yang di dapat sesuai dengan kesesuaiaan kondisi di divisi ITPS, dimana divisi ini memiliki project documentation untuk untuk stakeholder yang berisi User Guide, berita acara penyelesaian user acceptance test (BAP UAT), dokumen Test plan untuk menjaga kualitas dari sebuah proyek, dan dokumen change request berisi perubahan kebutuhan dan penambahan kebutuhan dari stakeholder. Mereka juga memiliki proses demo progress dalam tahap development agar hasil proyek sesuai 
dengan keinginan stakeholder, tahap User Acceptance Test (UAT) untuk meninjau kualitas dan kapabilitas project, dan juga tahap Early Life Support (ELS) yaitu pemeliharaan yang dilakukan oleh divisi ITPS dalam jangka waktu tertentu untuk membantu stakeholder yang mengalami kendala dan memastikan kualitas hasil dari proyek.

d. APO11.04 Perfom quality monitoring control and review.

Berdasarkan audit yang dilakukan pada cakupan sub domain APO11, Proses ini ada untuk mengukur sejauh mana pencapaian aktivitas yang ada di divisi dalam melakukan pemantauan kualitas, pengendalian dan ulasan. Hasil dan bukti yang di dapat sesuai dengan kondisi di divisi ITPS yaitu adanya dokumen sasaran mutu dalam bentuk file IT project roadmap \& allocation, dan IT Project Scoring, dan adanya penerapan pengendalian dalam pengerjaan proyek yaitu Work Breakdown Structure (WBS). Selain itu divisi ini memiliki program training untuk tiap bagian pekerjaan, dan setiap dokumen yang dikerjakan melalui proses review dari Chief IT Product Solution. Divisi ini juga memiliki project management tools untuk memantau pekerjaan yang sedang dilakukan, dan Adanya performance tools untuk mengukur kinerja pegawai yang ada. Akan tetapi Dokumen Evaluasi yang dimiliki belum sepenuhnya dilaksanakan dalam pengerjaan proyek.

e. APO11.05 Integrate quality management into solutions for development and service delivery.

Berdasarkan audit yang dilakukan pada cakupan sub domain APO11, Proses ini ada untuk mengukur sejauh mana pencapaian aktivitas yang ada di divisi dalam mengintegrasikan manajemen kualitas menjadi solusi untuk pengembangan. Hasil dan bukti yang di dapat sesuai dengan kesesuaiaan kondisi di divisi ITPS dimana setiap pengerjaan proyek berpedoman/mengacu pada SOP, WI, dan form di setiap modul proses bisnis, dan juga penerapan enterprise architecture pada setiap proses bisnis yang ada di divisi ITPS. Tetapi hal yang sering terjadi adalah Proses review dokumen membutuhkan waktu yang lama karena belum ada reviewer selain Chief IT Product Solution. Kemudian Belum semua proses bisnis terdokumentasi pada dokumen WI, akan tetapi semua hasil proyek dalam bentuk aplikasi sangat membantu setiap departemen.

f. APO11.06 Maintain continuous improvment.

Berdasarkan audit yang dilakukan pada cakupan sub domain APO11, Proses ini ada untuk mengukur sejauh mana pencapaian aktivitas yang ada di divisi khususnya untuk menjaga dan melakukan perbaikan terusmenerus. Hasil dan bukti yang di dapat sesuai dengan kondisi di divisi ITPS, dimana penerapan dokumen evaluasi dalam bentuk project lesson learned berisi kendala selama pengerjaan proyek dan dijadikan pembelajaran untuk proyek selanjutnya, mereka juga monitoring skill dan kompetensi pegawai berdasarkan hasil dari training yang ada. Divisi ITPS juga selalu melakukan perbaikan atau update untuk setiap SOP, WI, dan Form dalam setiap modul proses bisnis yang ada, serta menyusun dan melengkapi SOP untuk proses bisnis yang belum memiliki SOP ataupun belum lengkap. Tetapi kondisi yang ada setiap peawai di divisi ini belum/kurang memiliki kesadaran untuk memelihara dan meningkatkan manajemen kualtias yang sudah ada.

\subsection{Hasil Analisa COBIT 5}

\subsubsection{Analisis Capability Level}

Bedasarkan hasil data yang diperoleh dari proses observasi dan wawancara dan juga temuan didapat capability level 6 subproses APO11 berada di level 2 dan rating kriteria yaitu fully achieved (F) dimana pada subproses APO11.01 Establish a quality management system dan APO11.03 Focus quality managemen on customer rating kriteria largely achieved (L). Proses APO11 Manage Quality di divisi ITPS memiliki hasil capability level 2. Artinya divisi ITPS sudah memiliki sistem manajemen kualitas dan mampu mengimplementasikannya dengan baik, dan sudah mengelolanya dengan baik. APO11 sedang dalam tahap menuju capability level 3. Berikut di bawah ini gambar hasil capability level APO11. 


\begin{tabular}{|c|c|c|c|c|c|c|c|c|}
\hline \multirow{2}{*}{ Domain } & \multirow{2}{*}{ Proses Name } & \multirow{2}{*}{\begin{tabular}{|l} 
Target \\
Level \\
\end{tabular}} & \multicolumn{6}{|c|}{ Capability Level } \\
\hline & & & 0 & 1 & 2 & 3 & 4 & 5 \\
\hline \multirow{6}{*}{$\begin{array}{c}\text { Align, Plan, } \\
\text { Organise } 11 \\
\text { Manage Quality }\end{array}$} & APO11.01 Establish a quality management system. & 3 & & & $\mathrm{~L}$ & & & \\
\hline & $\begin{array}{l}\text { AP011.02 Define and manage quality standarts, } \\
\text { practices and procedures. }\end{array}$ & 3 & & & $\mathrm{~F}$ & & & \\
\hline & APO11.03 Focus quality management on customers. & 3 & & & $\mathrm{~L}$ & & & \\
\hline & $\begin{array}{l}\text { APO11.04 Perfom quality monitoring, } \\
\text { control and review. }\end{array}$ & 3 & & & $\mathrm{~F}$ & & & \\
\hline & $\begin{array}{l}\text { APO11.05 Integrate quality management into solutions } \\
\text { for development and service delivery. }\end{array}$ & 3 & & & $\mathrm{~F}$ & & & \\
\hline & APO11.06 Maintain continuous improvement. & 3 & & & $\mathrm{~F}$ & & & \\
\hline
\end{tabular}

\section{Gambar 2. Hasil Capability Level APO11}

\subsubsection{Analisis Kesenjangan (Gap)}

Menurut hasil analisis dan ditetapkannya capability level pada APO11 - Manage Quality telah diperoleh bahwa capability level APO11 berada pada level 2 (Manage process) artinya pelaksanaan proses TI terkelola dengan baik,mencapai tujuannya, dan melakukan evaluasi dan penyesuaian menuju ke arah yang lebih baik lagi.

Tabel 4. Analisis kesenjangan Capability Level APO11

\begin{tabular}{cccc}
\hline Process Name & Current Level & Target Level & Gap \\
\hline APO11 & 2 & 3 & 1 \\
\hline
\end{tabular}

Dari tabel 4 menjelaskan bahwa capability level target yang diinginkan adalah level 3 (Established process) yang berarti proses TI telah diidentifikasi dan dijalankan dengan prosedur standar formal dan terdokumentasi. Batasan ini merupakan hasil dari pengukuran yang telah dilakukan sebelumnya, dan agar dapat diukur sejauh mana proses tersebut mencapai tujuan proses untuk mendukung tujuan perusahaan dan dapat menghasilkan proses yang baik dan stabil. Gambar dibawah ini menunjukkan grafik capability level berisi selisih antara level kapabilitas saat ini dengan level kapabilitas yang diinginkan. Berdasarkan dari analisis hasil wawancara dan temuan menggunakan framework COBIT 5 khususnya subdomain APO11 menghasilkan nilai selisih (gap) sebesar 1 antara nilai level kapabilitas saat ini dengan nilai level kapabilitas yang akan dicapai (target).

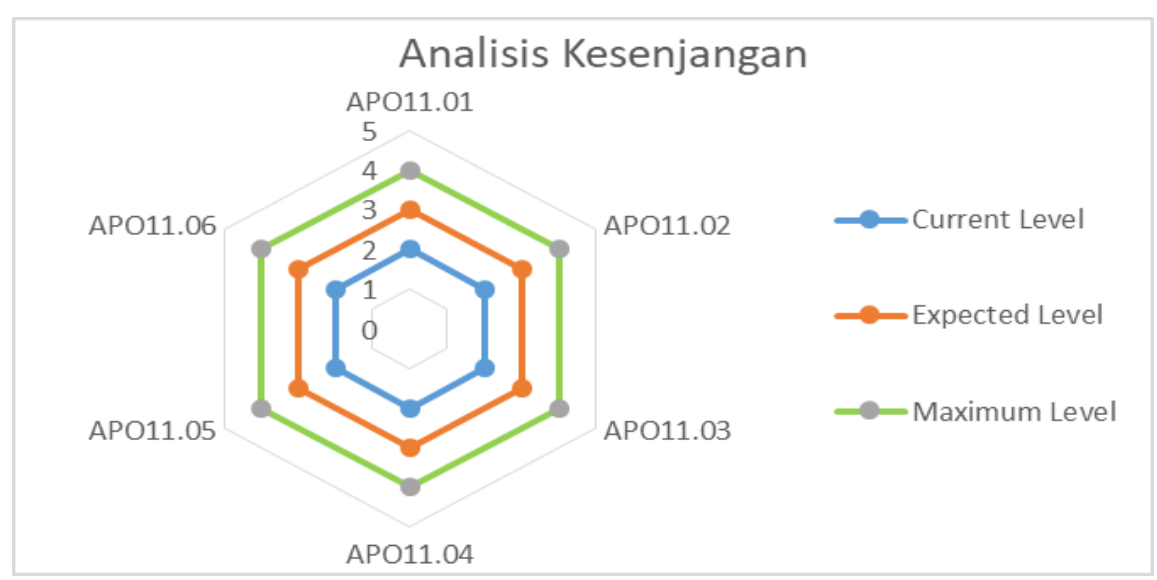

Gambar 3. Grafik Capability Level APO11

\subsubsection{Rekomendasi}

Berdasarkan hasil temuan dan hasil capability level yang didapat pada APO11. Capability Level yang didapat secara keseluhan adalah Level 2 (Manage Process), Level target yang ingin dicapai adalah 3 (Established process) sehingga rekomendasi yang dapat penulis berikan untuk manajemen kualitas yang ada di divisi ITPS. 
a. Divisi ITPS perlu meningkatkan performa proses manajemen kualitas dengan perlu dilakukan tindakan yang terukur dan tepat sasaran agar kualitas manajemen semakin baik dan setiap proses TI menjadi semakin efektif dan efisien.

b. Divisi ITPS perlu membuat SOP secara terpisah untuk mengukur performa proses pada proses bisnis yang ada terkait indikator performa, ukuran performa, dan tujuan peningkatan performa.

c. Meningkatkan monitoring terhadap proses TI yang berlangsung untuk mempertahankan kualitas yang sudah cukup baik di divisi IT Product Solution.

d. Melakukan terobosan dan inovasi baru terhadap proses bisnis agar berjalan variatif ke arah yang lebih baik di waktu mendatang.

e. Divisi ITPS perlu meningkatkan pengelolaan resource allocation setiap individu agar tidak ada proyek yang tertunda akibat adanya staff yang memiliki allocation yang melebihi kapasitasnya.

f. Divisi ITPS perlu membuka lowongan pekerjaan untuk mengatasi rangkap jabatan yang terjadi.

g. Melengkapi semua dokumen evaluasi untuk setiap proses pengerjaan proyek agar dapat dijadikan pengembangan untuk proyek selanjutnya.

h. Divisi ITPS perlu menyusun SOP baru untuk setiap proses bisnis yang belum memiliki SOP untuk menjaga mutu kualitas dari setiap proses bisnis.

i. Menambah jadwal training dan mentoring untuk staff baru, agar mereka dapat bekerja sesuai SOP dan meningkatkan kualitas manajemen yang ada.

\section{KESIMPULAN}

Berdasarkan audit yang dilakukan pada PT. Akur Pratama (Yogya Group) dalam study kasus divisi IT Product Solution dengan menggunakan framework COBIT 5 Domain Align Plan Organise (APO11) Manage Quality maka kesimpulan dari tugas akhir ini adalah

a. Telah melakukan audit sistem informasi di divisi ITPS PT. Akur Pratama (Yogya Group) dengan menggunakan framework COBIT 5 sehingga mendapatkan capability level atau tingkat kematangan yang berfokus pada subdomain APO11 Manage Quality.

b. Bedasrkan hasil audit, ditemukan beberapa temuan yang digunakan untuk menilai capability level proses area APO11 - Manage Quality pada divisi ITPS PT. Akur Pratama (Yogya Group), diperoleh hasil capability level 2, artinya pelaksanaan proses TI terkelola dengan baik,mencapai tujuannya, dan melakukan evaluasi dan penyesuaian untuk menuju ke arah yang lebih baik. Sedangkan capability level target yang diinginkan adalah level 3 (Established Process)

c. Dari perolehan capability level diatas, diketahui level kapabilitas divisi ITPS berada di level 2 (Manage Process) artinya divisi ini sudah memiliki sistem manajemen kualitas dan mampu mengimplementasikannya dengan baik, dimana dalam setiap implementasi proyek berdasarkan standar kualitas yang sudah ditentukan sebelumnya, sehingga proyek berjalan dengan baik dan hasil nya memberikan solusi IT yang tepat untuk departemen lainnya.

d. Untuk mencapai level target 3 (Established Process) rekomendasi yang diberikan untuk divisi ITPS adalah membuat Standard Operation Procedure (SOP) secara terpisah untuk mengukur performa proses pada proses bisnis yang ada terkait indikator performa, ukuran performa, dan tujuan peningkatan performa, dan dapat menyalurkan sumber daya yang lebih tepat di setiap aktivitas.

\section{DAFTAR PUSTAKA}

[1] Wella, (2016). Audit Sistem Informasi Menggunakan COBIT 5.0 Domain DSS pada PT Erajaya Swasembada, Tbk. Tangerang: Universitas Media Nusantara. (Vol. VII, No. 1)

[2] Juliandarini. Handayaningsih, Sri, (2013). Audit Sistem Informasi pada Digilib Universitas XYZ Menggunakan Kerangka Kerja COBIT 4.0. Yogyakarta: Universitas Ahmad Dahlan. (Vol. 1, No. 1)

[3] Weber, Ron, (1999). Information System Control and Audit. Queensland: Prentice Hall.

[4] Pragita, Cantika, Dkk. (2014). Analisis Audit Sistem Informasi Pada Domain APO (Align, Plan and Organise) Manage Quality Dengan Menggunakan Cobit Framework. Bandung: Universitas Telkom Bandung. (Vol.1, No.1).

[5] Irwanto, Aris, Dkk. (2017). IT Process dari COBIT 5 untuk Audit Sistem Informasi Keuangan dalam Audt Laporan Keuangan. Jakarta: Jurnal Univeristas Muhammadiyah.

[6] Faizin, Nur, Ilham. M, Dkk. (2015). Pembangunan Tools Audit Sistem Informasi Berdasarkan COBIT 5 pada Domain Align, Plan, And Organize (APO). Surabaya: Universitas Airlangga. (Vol. 1, No. 2).

[7] Abbott, Andrew. (2001). Time Matters: On Theory and Method. Chicago \& London: The University of Chicago Press.

[8] Sukmadinata, Syaodih, Nana. (2011). Metode Penelitian Pendidikan. Bandung: Remaja Rosdakarya.

[9] ISACA. (2012). COBIT 5 : Process Assessment Model (PAM). USA: ISACA. 
Jurnal SITECH, Vol 2, No 1, Juni 2019

P-ISSN : 2615-8531, E-ISSN : 2622-2973

[10] Omari, Al, Dkk. (2012). Optimising COBIT 5 for IT Governance. Queensland: Queensland University of Technology. (Vol. 2, No.1).

[11] ISACA, (2012). COBIT 5: A Business Framework for the Governance and Management of Enterprise IT. USA: ISACA.

[12] IT Product Solution, (2018). Handbook For New Employee First Edition. Bandung: IT Product Solution. 